\title{
The Order of Knowledge: From Disciplinarity to Transdisciplinarity and Back
}

\author{
J ÜR GEN MITTELSTR ASS \\ Department of Philosophy, University of Konstanz, D-78547 Konstanz, Germany. \\ Email: juergen.mittelstrass@uni-konstanz.de
}

\begin{abstract}
The concept of transdisciplinarity has found a foothold in science. It is increasingly taking the place of the concept of interdisciplinarity and is making the concept of disciplinarity look pale. However, the concept of transdisciplinarity is not self-explanatory - as it is often understood - and the concept of disciplinarity is not at all outdated - as it seems. This becomes clear in the conceptual analysis of the concepts of disciplinarity, interdisciplinarity and transdisciplinarity.
\end{abstract}

\section{Preliminary Remarks}

For centuries, the order of knowledge seemed to be taken for granted, almost as something natural, especially when we think of the way research and teaching at universities is structured. This structure was given by an order of disciplines, structured in subjects, which followed their own respective theoretical and methodological standards. Interdisciplinarity, as part of this structure, was accordingly the dialogue between disciplines, sometimes less and sometimes more intense, but always conducted from the safe viewpoint of the respective disciplines. Examples for this are a studium generale, which used to be mandatory, and lecture series between disciplines, which were from the beginning defined as not mandatory.

This has since changed. Interdisciplinarity has suddenly become widely discussed. Academia preaches it where programme reform is concerned, and science in particular when advertising its research. ${ }^{1}$ But even so, this does not yet seem satisfying. The further concept of transdisciplinarity is being introduced, and is usually used to counteract the old-fashioned, non-binding nature of the concept of interdisciplinarity with the idea of a binding form of cooperation that is almost enforced by the development of science itself. In transdisciplinarity, the disciplines lose their formerly 
dominant role. Whoever wants to show their inclusiveness in science speaks of interdisciplinarity, and whoever wants to show that they are at the methodological forefront speaks of transdisciplinarity. Even within science policy, transdisciplinarity is used when trying to give an impression of theoretical sophistication. It often appears that what is meant by what is now called transdisciplinarity, is as self-evident as interdisciplinarity. However, this is not true when we take a closer look. While there are attempts to define transdisciplinarity as an elaborated methodology and to recommend it to the sciences, this rests more on a misunderstanding than an insight, i.e. the misunderstanding that transdisciplinarity is something that can be formulated in theoretical, here methodological, form. I will return to this later.

\section{Disciplinarity and Interdisciplinarity}

The sciences are organized by subjects and disciplines. Geometry is a subject in the discipline of mathematics, and English Studies is a subject in the disciplines of literature and linguistics. Those who teach at university teach a subject within a discipline, and whoever attends a university studies a subject within a discipline. So far, everything seems in order. There is a firm scientific architecture, which is expressed institutionally in the form of institutes (colleges, schools) and departments or faculties (discipline structure). This is what I call the epistemic and the organizational structure of science. The one, the epistemic structure, concerns the order of knowledge, while the other, the organizational structure, concerns the institutional order of subjects and disciplines within the university. What is interdisciplinarity in this context, and why is it so important?

Interdisciplinarity is, as strange as this may at first sound given its current popularity, really an ancient idea of science. However, it presented itself in a very different way from today and concerned the fact that the knowledge of various disciplines was closely linked, that the path into one discipline also led into other disciplines, that specialists did not yet exist, and that science was philosophy and philosophy was science. However, it was particular individuals (for example Aristotle) who held all the knowledge together, even in the disciplinary forms that were soon emerging, and not a scholarly architecture that dictated its structure. The unity of science, which is still occasionally talked about, was less an idea - which it was to become later - but simply reality.

Interdisciplinarity, understood simply as a path between the disciplines, neither has in this sense its own epistemic and organizational status, nor does it support further scientific development, for example, as a particular form of competence. Rather, it turns out to be a kind of competence to unite where disciplinary knowledge goes its own way and separates itself from other disciplinary knowledge, where it develops diversity in the form of intradisciplinary special forms, and where Aristotelian universality is missing.

Now, it would be profoundly unrealistic to think that we would only have to find universal thinkers such as Aristotle again for interdisciplinarity to once more become nothing particularly noteworthy. The cosmos of scientific knowledge has expanded too much and has become too diverse. Moreover, science is not only about answering 
one's own questions and solving one's own problems with the appropriate disciplinary means, but it is also more and more about helping to answer questions and to solve problems outside the inner-world of science; that is, in ordinary life, in the natural as well as in the social realm. The scientific world is not a closed world, for which the well-known metaphor of the ivory tower stands, but it is - whether science likes it or not - an open world.

This is true not only in organizational or institutional respects, but also in epistemic respects: at least in the sense that it is not always possible to sharply distinguish answering questions and giving solutions to problems as scientific questions and problems that concern science at its core, from answering such questions and offering solutions that concern the world. Nuclear research, in the form of fusion research, for example, is not pursued for its own sake, i.e. which is only interesting to the researcher, but also for solving our energy problems, which is of interest to us all. The same applies to medical and climate research. Here, too, it is not so much a matter of solving problems that are inner-scientific, and thereby 'invented' by the scientific community, but rather a matter of solving the most problematic health and environmental problems.

That science is increasingly divided into professional and disciplinary specializations is also unsurprising. This fact is not a result of an unwanted development, which would have to be corrected by means of interdisciplinary measures, but by progress in science. Development into subjects and disciplines is here the consequence of scientific success, which is often not in the core area of a subject or discipline where textbook knowledge is located, but rather in peripheral areas that can be closer to other subjects and disciplines than one's own subject or discipline. This is true in both substantial and theoretical or methodological respects. Neither the subjects of research nor the theories and methods used in research are generally mutually exclusive or disciplinary. The same objects, e.g. plant structures, can be the interest of different subjects and disciplines. The same theories, e.g. mathematical theories, and the same methods, e.g. empirical methods, can prove fruitful across many subjects and disciplines. Moreover, specialization does not only have to take place within a discipline, it often also takes place between subjects or disciplines. 'Nano' could be a keyword here. Interdisciplinarity, in turn, is expected to reconcile the different epistemic and organizational or institutional structures. But is that enough?

\section{Transdisciplinarity}

Given the developments described above, the scientific system has become alarmingly complex. ${ }^{2}$ This is true not only as regards the tremendous growth of knowledge, which one could not follow in all detail even within the narrower context of a subject, but also as regards the institutional structure of science. The specialization of subjects reaches even into the naming of university chairs. The ability to think within a larger scientific unit, such as a discipline, let alone to think beyond one, is decreasing alarmingly. But this means that the boundaries of subjects and of disciplines, if still 
correctly perceived at all, increasingly threaten to become not only institutional boundaries, but also the limits of knowledge.

Here, we should remember that the subjects and disciplines of science are nothing 'natural' or 'god given', but are something that came about from the history of science, and that their boundaries are often not theoretical, i.e. systematically determined, but are rather historical. Their scientific-historical identity is also defined by certain research subjects, theories, methods, and research purposes, which often do not together form a specialization or discipline - as I have already mentioned - but interfere at an interdisciplinary level. This is illustrated not only by the fact that disciplines in their work are guided by methodological and theoretical ideas, which they themselves could not produce independently, but also by the fact that problems, and thus their solutions, can change the framework of their discipline or subject. A good example of this is the theoretical description of heat. Heat was regarded first as the inner movement of matter and thus as the object of physics. With the caloric theory, developed by the Dutch physician and scientist Boerhaave at the beginning of the eighteenth century and further developed by the French chemist Lavoisier, heat - because it was now understood as being matter - then became the object of study in chemistry. Finally, with the kinetic theory of heat, heat again changed disciplines and once again became an object of study in physics. This shows that the objects of research (alone) do not define the discipline, but the way in which we theoretically deal with them does. This is clear for research, but often not for a discipline's self-image.

This example can be generalized and at the same time applied to the common world, i.e. not only to scientifically defined problems, in such a way that certain problems escape the access of a single subject or discipline. And these are often by no means marginal, but rather central problems, such as those concerning the environment, energy and health. There is an asymmetry regarding the development of problems and of disciplines (or subjects), and this is exacerbated by the fact that development of disciplines and subjects is determined by growing specialization. Ecological problems, for instance, are complex problems; as we all now know, they can only be solved by the cooperation of the competences of many subjects and disciplines, which are usually specialized competences. The same is true of energy and health, as well as many other areas that cannot make progress without science. If, therefore, the problems do not do us the favour of defining themselves as disciplinary or as falling under one subject, then we also need special efforts that usually lead us away from subjects or disciplines. This is precisely what the term 'interdisciplinarity' has so far been used for, and it is exactly what the term 'transdisciplinarity' is used for today. However, this is not just a semantic change.

While scientific cooperation in the form of interdisciplinarity usually means temporary cooperation, transdisciplinarity means that cooperation leads to a permanent scientific order that changes the structure of the subjects and disciplines. Transdisciplinarity is presented as a form of carrying out research, thus as a form of science when it concerns problems of the common world, e.g. to solve the environmental, energy and health problems mentioned above, and also when it concerns the order of scientific knowledge and scientific research itself. In both cases, transdisciplinarity 
is a research or science principle, and not a theory principle. It is relevant where the definition of a problem or the solution to a problem within a subject or discipline is not possible, or where the definition of problems or solutions lead beyond subjects or disciplines. $^{3}$

In other words, transdisciplinarity, as portrayed here in contrast to interdisciplinarity, is, first, an integrative concept. It eliminates isolation that has emerged in scientific practice and can often only be explained historically, at a higher methodological level, but it does not pursue a universal interpretation and explanation pattern. Second, transdisciplinarity eliminates shortcomings that evolved over time where subjects and disciplines have lost their historical memory and problem-solving power because of too much specialization. But transdisplinarity does not lead to a new subject or discipline and, therefore, it cannot replace old subjects and disciplines. Third, transdisciplinarity is a research and organizational principle that, in being problem-oriented, goes beyond subjects and disciplines. However, it is not a transscientific principle that goes beyond science. Transdisciplinarity is a scientific view, and it is directed at a world that is a scientific and technical entity, being more and more the work of scientific and technical reason. Fourth, and finally, transdisciplinarity is, as I have mentioned already, first and foremost a research principle, not a theory principle. It is, at most, secondarily a theory principle, if the theories also follow transdisciplinary research programmes. Depending on whether a solution is a solution to an inner-scientific problem, i.e. a problem formulated by science itself, or a problem given by the world, I would like to speak of theoretical and practical transdisciplinarity respectively, both of which can go hand in hand, where theoretical transdisciplinarity can also serve practical transdisciplinarity.

\section{Institutional Consequences}

Theoretical and practical transdisciplinarity, which are increasingly becoming a requirement for theoretical and practical problem solving, while also following the scientific order of the theoretical and the practical, will in the future have to lead to new forms of organization in which the boundaries between subjects and disciplines fade into one research perspective. There have long been successful examples, as with the scientific centres in Berkeley, Chicago, Harvard, Princeton and Stanford, whose work addresses questions that cannot be assigned to a specific subject or discipline, e.g. as in the case of structural research, i.e. the development, analysis, manipulation and, ultimately, the practical application of structures of a certain order of magnitude, which is equally interesting for physics, chemistry and biology but also for geology as well as material and computer science. ${ }^{4}$ Such centres are also no longer organized according to the traditional structure of physics, chemistry, biology, and other institutes or faculties, but under a transdisciplinary perspective that follows the actual development of science. This is also the case where single problems rather than far-reaching programmes are the main focus, as in the case of the 'Bio-X' centre at Stanford (Ref. 4, p. 3), or the 'BIDMC Genomics, Proteomics, Bioinformatics and Systems Biology Center' at Harvard. ${ }^{5}$ Here, biologists use sophisticated physical and 
chemical methods to elucidate the structure of biologically relevant macromolecules, and physicists - such as Nobel laureate Steven Chu, one of the initiators of the 'Bio-X' programme - manipulate biological objects with state-of-the-art physical methods (Ref. 4, p. 3). Disciplinary competences remain an essential requirement for transdisciplinarily defined tasks, but they are no longer sufficient to successfully handle research tasks that grow out of the classical subjects and disciplines. And what applies to work on scientific problems should also apply to (scientific) work on the world's problems.

This, however, means that the logic underlying the current institutional development of the scientific system is being questioned. This underlying logic has led to an isolation of subsystems, where networking at a low institutional level should be the slogan, not the expansion of system independences at a high institutional level. This means that temporary institutionalized research groups should replace increasingly isolated scientific subsystems, and that the institutional order of subjects and disciplines must become flexible within a subsystem such as the university. The reasoning is simple from the point of view of research and science: the system of science must move when research moves. Currently, things are rather the other way around: research is not seeking its order, rather, an order given by the subsystems and substructures (I mention only the institutes of the Helmholtz Society and the Max Planck Society in Germany) is looking for its research. Such a scientific order, which is wedded to its institutional habits, is counterproductive. This, however, cannot be the future of research and the scientific system. As can be seen, the increasing scientifically-driven transdisciplinarity of scientific research has far-reaching institutional consequences, or should have such consequences.

\section{Concluding Remarks}

The game of disciplines with inter- and transdisciplinarity, in analogy to Karl Popper's talk of 'the game of science, ${ }^{6}$ is a serious game. Not only are the scientific (epistemic) cards shuffled again, but so too are the institutional cards. The times are over in which lecture series between disciplines, or studium generale that supplements the curriculum, have fulfilled the need for interdisciplinarity or even transdisciplinarity. Scientists never really took them seriously with regard to the intention to learn about, and, if necessary, to shift the boundaries of subjects and disciplines. In contrast, they may still have a certain appeal for a public interested in science. The public only attend them without commitment, to satisfy their academic curiosity, and to gain ideas without having to integrate them as part of their own knowledge. And this of course applies in particular if it is not only about interdisciplinarity in the usual sense, but about transdisciplinarity in the sense described above. This transdisciplinarity could also be described as strong interdisciplinarity, insofar as it is not only an easy, interdisciplinary mingling, but a serious cooperation that goes beyond one's own subject and disciplinary boundaries, thereby shifting these boundaries.

It has already been said that the disciplines do not lose their meaning in this process. They form the basis of scientific processes, without which transdisciplinarity 
in research and teaching would be a vain game with half-truths and alleged metacompetences. In contrast to the common assumption, the concept of a discipline is no less demanding than the concept of transdisciplinarity. We cannot do with a simple distinction between different subject areas, i.e., in epistemic terms, with simple realistic assumptions (in the sense of an ontological realism). Nature does not distinguish between physical, chemical and biological properties in terms of objects specific to each subject or discipline. If physics, chemistry and biology make the distinction in a disciplinary way, the justification of this must be given on different grounds.

In fact, it is about the constitutive features of the concept of a discipline that are not simply given but are the result of conceptual work. These include norms of object constitution, method explication and theory building, as well as an interest in knowledge that is methodological and theoretical. When it was previously said that subjects and disciplines are not 'natural', but rather something that is historically constrained by the history of science, and whose boundaries are often not theoretical but historical, this does not mean that the significance of subjects, and especially of disciplines, should be underestimated. Rather, this should point to a systematic constitutive task beyond the assumption of realism. Only the fact that this task has been solved in various ways in scientific development and will probably be solved in a variety of ways in the future makes the historical character of the building of disciplines. ${ }^{7}$ The fundamental role of disciplinary forms of scientific knowledge remains unaffected, also under transdisciplinary aspects. However, transdisciplinarily-defined tasks at the same time increase the demands on the conceptual clarity of disciplinarity, interdisciplinarity and transdisciplinarity, both in epistemic and institutional terms. This is what the title 'from disciplinarity to transdisciplinarity and back' was meant to express. The 'back' concerns the recovering of a viable disciplinary concept within the context of transdisciplinarity. Science is not easy, even when it is concerned with itself.

\section{References and Notes}

1. I use here and in the following the term 'science' in a broad sense, according to the German term 'Wissenschaft', i.e. including the humanities and arts.

2. See J. Mittelstrass (1993) Interdisziplinaritaet oder Transdisziplinaritaet?. In: L. Hieber (Ed.), Utopie Wissenschaft. Ein Symposium an der Universitaet Hannover ueber die Chancen des Wissenschaftsbetriebs der Zukunft (21/22. November 1991) (Munich and Vienna: Profil), pp. 17-31, also in: J. Mittelstrass (1998) Die Haeuser des Wissens: Wissenschaftstheoretische Studien (Frankfurt/Main: Suhrkamp), pp. 29-48.

3. For different views on the concept of transdisciplinarity and related problems see G. Hirsch Hadorn et al. (Eds) (2007) Handbook of Transdisciplinary Research (Heidelberg: Springer); J.T. Klein (2008) Evaluation of interdisciplinary and trandisciplinary research. American Journal of Preventive Medicine, 35, Supplement, pp. 116-123.

4. See, L. Garwin (1999) US universities create bridges between physics and biology. Nature, 397(7 January), p. 3. 
5. See, D. Malakoff (1999) Genomic, nanotech centers open: $\$ 200$ million push by Harvard. Science, 283(29 January), pp. 610-611.

6. K.R. Popper (1959) The Logic of Scientific Discovery (London: Hutchinson), p. 53.

7. See C.F. Gethmann (2015) Disciplinary - interdisciplinary - transdisciplinary: a conceptual analysis. In: C.F. Gethmann et al. (Eds), Interdisciplinary Research and Transdisciplinary Validity Claims (Heidelberg: Springer), pp. 39-60.

\begin{abstract}
About the Author
Jürgen Mittelstrass is Professor emeritus of Philosophy at the University of Konstanz. From 1985 to 1990 he was a member of the German Science Council (Cologne), and from 2005 to 2015 President of the Austrian Science Council (Vienna). He was also, from 1997 to 1999, President of the German Philosophical Association, and from 2002 to 2007 President of the Academia Europaea (London). He won the 1989 Leibniz Prize of the German Research Society; the 1998 Lorenz Oken Medal of the Society of German Scientists and Physicians; the 2012 Nicholas Rescher Prize for Systematic Philosophy. His publications include: Die Rettung der Phaenomene (1962), Neuzeit und Aufklaerung (1970), Die Moeglichkeit von Wissenschaft (1974), Der Flug der Eule (1989), Geist, Gehirn, Verhalten (with M. Carrier, 1989, in English, enlarged, Mind, Brain, Behavior, 1991), Leonardo-Welt (1992), Die Haeuser des Wissens (1998), Wissen und Grenzen (2001); Leibniz und Kant (2011), Die griechische Denkform (2014), and as editor: Enzyklopaedie Philosophie und Wissenschaftstheorie, 4 vols (1980-1996), 2nd edn, 8 vols (2005-2018).
\end{abstract}

